\title{
The effect of CyberKnife therapy on pulmonary function tests used for treating non-small cell lung cancer: a retrospective, observational cohort pilot study
}

\author{
This article was published in the following Dove Press journal: \\ Cancer Management and Research \\ 9 October 2012 \\ Number of times this article has been viewed
}

\author{
Rishi Agarwal',2 \\ Paramveer Saluja' \\ Angela $\mathrm{Pham}^{3}$ \\ Karen Ledbetter ${ }^{3}$ \\ Sukhveer Bains ${ }^{3}$ \\ Seema Varghese ${ }^{3}$ \\ John Clements' \\ Young $\mathrm{H} \mathrm{Kim}^{4}$ \\ 'Synergy Medical Education Alliance, \\ Michigan State University College of \\ Human Medicine, Saginaw, Michigan, \\ USA; ${ }^{2}$ MD Anderson Cancer Center, \\ Houston, Texas, USA; ${ }^{3}$ Michigan State \\ University, Saginaw, Michigan, USA; \\ ${ }^{4}$ Seton Cancer Institute, Saginaw, \\ Michigan, USA
}

\begin{abstract}
Introduction: The current standard for treating operable early stage non-small cell lung cancer is surgical resection and for inoperable cases it is external beam radiotherapy. Lung functions are adversely affected with both the above treatments. CyberKnife treatment limits radiation damage by tracking targets moving with each breath. The effect of CyberKnife treatment on pulmonary function tests has not been well documented.

Methods: Lung cancer patients who underwent CyberKnife treatment and had pre- and posttreatment pulmonary function tests were included. Paired $t$-tests were conducted. We also conducted subgroup analysis.
\end{abstract}

Results : Thirty-seven patients were included. Median age was 73 years. No statistical difference between mean pre- and post-CyberKnife pulmonary function tests was found.

Discussion: We observed that CyberKnife better preserves lung function status compared to current standards of care. It has shown to have very minimal side effects.

Keywords: non-small cell lung cancer, radiation pneumonitis, radiotherapy, pulmonary function tests

\section{Introduction}

More cancer patients die of lung cancer than of any other cancer. ${ }^{1,2}$ Early detection and treatment has shown overall improved outcomes in patients with lung cancer. ${ }^{3,4}$ The current standard of care for early stage non-small cell lung cancer (NSCLC) is invasive local control through surgical resection typically by lobectomy. ${ }^{3}$ Significant decrease in pulmonary function after lobectomy has been noted in earlier studies. ${ }^{5,6}$ Win et al found that NSCLC patients who underwent lobectomy "suffered a significant reduction of pulmonary reserve" and lost a great deal of lung function and exercise capacity. ${ }^{6}$ Functional lung status was measured using pulmonary function tests (PFT) in these studies.

For patients with stage 1 NSCLC who are inoperable or do not want to undergo surgery, external beam radiotherapy is the next best treatment as per the current standards. However, conventional radiotherapy has a high local failure rate of $6.4 \%-70 \%$ and has an estimated five-year overall survival rate of $21 \% \pm 8 \%$. Symptomatic radiation pneumonitis is present in $5 \%$ to $30 \%$ of patients receiving radiotherapy for thoracic malignancies. In addition, $50 \%$ to $90 \%$ of patients experience declines in pulmonary function test measurements. ${ }^{8-13}$ The decrease in lung function in both surgical and radiotherapy therapy patients is very significant considering that
Correspondence: Rishi Agarwal 7675 Pheonix Drive, Apt \# 913, Houston, Texas, USA-77030

Tel +l 9892939137

Email drrishiagarwal@gmail.com 
most lung cancer patients already have poor lung function as most of them also have a history of smoking. Reducing the morbidity of treatment could possibly improve the quality of life in the survivors. There have been significant advances in treatment technology in recent years that will reduce damage to healthy lung tissue during NSCLC treatment by surgery or radiotherapy. One such treatment is CyberKnife.

CyberKnife is a noninvasive, highly specific radiological method of treating cancer tissue with relative preservation of the surrounding healthy tissues. It has been approved and used to treat early stage NSCLC with excellent results. CyberKnife has the unique ability to track dynamic targets that move with breathing. Thus it limits radiation exposure and damage to normal tissue. ${ }^{14}$ Despite its great promise in treatment of lung cancer, no previous studies have specifically documented CyberKnife's effect on pulmonary function studies. This study aims to confirm that in treatment of lung cancer, especially early stage, CyberKnife preserves lung function better than the current standard of care. The objective is to compare pre- and post-PFTs of patients treated with CyberKnife for lung cancer and ascertain how much lung function is preserved after the treatment.

\section{Methods and materials}

This is an Internal Review Board-approved, retrospective, observational cohort study of patients diagnosed with lung cancer to determine if there are differences in lung function before and after radiosurgery using CyberKnife. Pulmonary function tests were performed on the group before CyberKnife treatment and repeated 3-4 months after treatment.

We included patients diagnosed with primary or metastatic lung cancer who opted for CyberKnife treatment and had pre- and post-treatment pulmonary function tests. We excluded patients who did not fulfill the above criteria.

Abstracted data was entered into a Microsoft Access database and transferred to SPSS statistical software (v 20.0; IBM Corporation, Armonk, NY). Analysis included generation of descriptive statistics to adequately describe the sample. We also conducted paired $t$-tests to determine differences in pulmonary function data pre- and postoperatively (at 3 to 4 months). In addition, we conducted subgroup analysis based on gender, location, and stage of tumor. We compared eleven parameters of pulmonary function tests including: forced vital capacity (FVC), forced expiratory volume in 1 second $\left(\mathrm{FEV}_{1}\right), \mathrm{FEV}_{1} / \mathrm{FVC}$ ratio, forced expiratory flow $25 \%-75 \%$, forced inspiratory vital capacity, slow vital capacity, inspiratory capacity, expiratory reserve volume, diffusing capacity of the lung for carbon monoxide, diffusion capacity corrected for alveolar volume, and alveolar volume.

\section{Results}

Thirty-seven patients were included in the study. The median age of the group was 73 years (Table 1). Approximately 49\% of the subjects were female, while $51 \%$ were males. Three patients were given $5000 \mathrm{cGy}$ in five divided fractions and 34 patients received $6000 \mathrm{cGy}$ in five divided fractions. All the patients had smoking history. Stage 1 cancer was documented in 22 patients, stage 2 in two patients, stage 3 in five patients and stage 4 cancer in eight patients. The location of the tumors is mentioned in Table 1.

Paired $t$-tests indicated that there was no statistical difference between pre-CyberKnife and post-CyberKnife treatment in terms of mean PFTs for the overall group (Table 2) and for subgroups based on gender and tumor location.

Analysis of subgroups based on stage indicate that stage 4 PFTs were significantly decreased for FVC, but significantly increased for the $\mathrm{FEV}_{1} / \mathrm{FVC}$ ratio, at 3 months compared to zero months (Figure 1).

\section{Discussion}

CyberKnife treatment has been shown to be very effective for stage 1 NSCLC in multiple studies published in last few years. ${ }^{15-19}$ In our study, we observed that CyberKnife is successful in preserving lung function status as was measured by pulmonary function tests. This observation supports the emerging role of CyberKnife in lung cancer management.

Our results are in line with the conclusions of Stephans et al, who studied Novalis treatment (another stereotactic body radiation therapy) and found no significant differences in

Table I Patient characteristics

\begin{tabular}{ll}
\hline Age (median) (years) & 73 \\
Male-n (\%) & $19(5 \mathrm{I})$ \\
Smoking-n (\%) & $37(100)$ \\
Location & \\
$\quad$ Left upper lobe-n (\%) & $13(35)$ \\
Left lower lobe-n (\%) & $4(1 \mathrm{I})$ \\
Right upper lobe-n (\%) & $7(20)$ \\
Right medial lobe-n (\%) & $1(3)$ \\
Right lower lobe-n (\%) & $10(30)$ \\
Right hilar lymph nodal region-n (\%) & $2(5)$ \\
Stage & \\
Stage I-n (\%) & $22(59)$ \\
Stage II-n (\%) & $2(5)$ \\
Stage III-n (\%) & $5(14)$ \\
Stage IV-n (\%) & $8(22)$ \\
Dose of radiation received & \\
5000 cGy-n (\%) & $3(8)$ \\
6000 cGy-n (\%) & $34(92)$ \\
\hline
\end{tabular}


Table 2 Comparison of pulmonary function tests pre- and postCyberKnife treatment

\begin{tabular}{|c|c|c|c|c|}
\hline \multicolumn{5}{|c|}{$\begin{array}{l}\text { Pulmonary function test results } \\
\text { Pre-CyberKnife vs 3-4 months post-Cybe }\end{array}$} \\
\hline $\begin{array}{l}\text { PFT parameter } \\
\text { (percentage } \\
\text { of predicated) }\end{array}$ & Mean & $\begin{array}{l}n \text { (number } \\
\text { of patients) }\end{array}$ & $\begin{array}{l}\text { Standard } \\
\text { deviation }\end{array}$ & $P$-value \\
\hline FVC - pre & 76.2 & 37 & 21.6 & 0.346 \\
\hline FVC - post & 74.2 & 37 & 19.6 & \\
\hline $\mathrm{FEV}_{1}$ - pre & 56.5 & 37 & 22.1 & 0.781 \\
\hline $\mathrm{FEV}_{1}$ - post & 56.2 & 37 & 21.9 & \\
\hline $\mathrm{FEV}_{1} / \mathrm{FVC}$ - pre & 74.6 & 37 & 17.9 & 0.905 \\
\hline $\mathrm{FEV}_{1} / \mathrm{FVC}$ - post & 74.8 & 37 & 18.0 & \\
\hline FEF - pre & 29.4 & 37 & 21.7 & 0.478 \\
\hline FEF - post & 31.0 & 37 & 20.9 & \\
\hline FIVC - pre & 2.1 & 33 & 0.7 & 0.189 \\
\hline FIVC - post & 2.2 & 33 & 0.8 & \\
\hline SVC - pre & 75.1 & 35 & 17.8 & 0.383 \\
\hline SVC - post & 76.9 & 35 & 17.7 & \\
\hline IC - pre & 74.9 & 32 & 17.8 & 0.267 \\
\hline IC - post & 72.1 & 32 & 20.9 & \\
\hline ERV - pre & 106.9 & 32 & 146.8 & 0.668 \\
\hline ERV - post & 112.7 & 32 & 92.0 & \\
\hline DLCO - pre & 56.1 & 33 & 24.4 & 0.672 \\
\hline DLCO - post & 54.8 & 33 & 19.8 & \\
\hline DLVA - pre & 79.6 & 32 & 30.5 & 0.287 \\
\hline DLVA - post & 90.8 & 32 & 53.5 & \\
\hline VA - pre & 71.1 & 32 & 19.1 & 0.299 \\
\hline VA - post & 67.0 & 32 & 21.4 & \\
\hline
\end{tabular}

Abbreviations: PFT, pulmonary function test; FVC, forced vital capacity; $\mathrm{FEV}_{1}$, forced expiratory volume in I second; FEF, forced expiratory flow; FIVC, forced inspiratory vital capacity; SVC, slow vital capacity; IC, inspiratory capacity; ERV, expiratory reserve volume; DLCO, diffusing capacity of the lung for carbon monoxide; DLVA, diffusion capacity corrected for alveolar volume; $\mathrm{VA}$, alveolar volume.

PFT pre- and posttreatment. ${ }^{20}$ In Novalis treatment usually an abdominal compression devise is used to limit patients' respiration, increasing patient discomfort. CyberKnife treatment does not need any method to limit breathing because of its tumor-tracking ability. Collins et al reported similar results

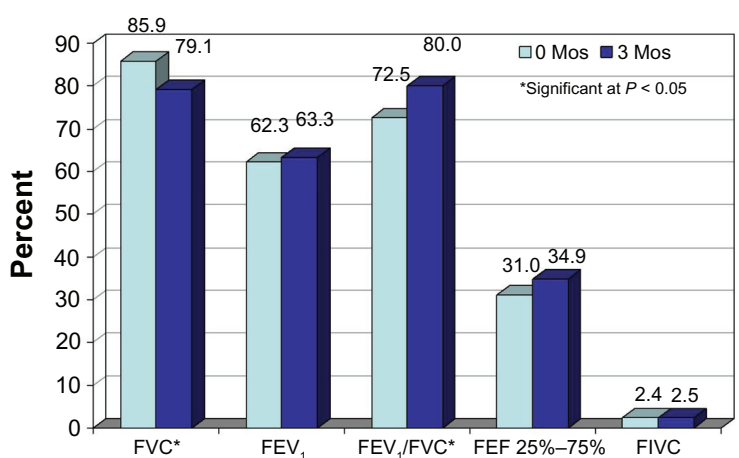

Figure I Comparison of mean pulmonary function tests before and 3-4 months after CyberKnife treatment in a stage 4 patient.

Abbreviations: Mos, months; FVC, forced vital capacity; $\mathrm{FEV}_{1}$, forced expiratory volume in I second; FEF, forced expiratory flow; FIVC, forced inspiratory vital capacity. for FVC and $\mathrm{FEV}_{1} \cdot{ }^{19}$ They also reported other side effects of CyberKnife treatment being pneumothorax and radiation pneumonitis. They did show a decrease in diffusing capacity of the lung for carbon monoxide at 6 months in the treated patients. ${ }^{19}$ We did not see any such decrease at 3 months. We will continue to collect long-term follow-up data on our patients to determine if any changes in lung function occur longitudinally.

Most of the patients in the study were referred to a radiation oncology department after they were considered not eligible for surgery or the patient opted for radiation treatment. CyberKnife was offered to these patients because of decreased duration of treatment, convenience to the patient, and possibility of decreased damage to normal lung tissue.

The small sample size, nonrandomization, and retrospective nature of our study are certain limitations of our study and interpretation of the results should be made with caution. Prospective randomized trials comparing CyberKnife to conventional radiotherapy, other types of stereotactic body radiation therapies, and surgical treatments could further clarify the role of CyberKnife treatment.

\section{Conclusion}

In our study, we observed that CyberKnife was successful in preserving lung functions at 3-4 months, unlike the current standards of care, and also has a better side-effect profile. Compared to other methods of stereotactic body radiotherapy, it is more comfortable, as it does not need any methods or devices to restrict the patient. The CyberKnife has proved to be a safe and effective treatment. Our study is limited by a small sample size and the results should be interpreted with caution. More research is needed in this field.

\section{Authors' contributions}

YHK is the principal author and designed the study. RA is the first author and contributed in data collection, literature search, and manuscript writing. AP, KL, SB, and SV contributed in study design and data collection. PS contributed in data collection and manuscript writing. JC contributed in study design and data analysis.

\section{Authors' information}

YHK is a radiation oncologist at Seton Cancer Institute in Saginaw, Michigan. RA and PS are third year internal medicine residents at Synergy Medical Education Alliance/ MSUCHM. AP, KL, SB, and SV are medical students at Michigan State University. JC is a research manager at Synergy Medical Education Alliance/MSUCHM. 


\section{Acknowledgments}

Rishi Agarwal wishes to thank Dr Babu Paidipaty, a pulmonologist who helped in the understanding of PFTs and was instrumental in manuscript writing. RA also wants to thank Dr Ernie Balcueva who helped in manuscript writing, and Carol Wahl, an administrator at Seton Cancer Institute who was instrumental in data collection.

\section{Disclosure}

Dr Kim is a radiation oncologist at Seton Cancer Institute and uses CyberKnife for his patients. The authors report no conflicts of interest in this work.

\section{References}

1. Parkin DM, Bray F, Ferlay J, Pisani P. Global cancer statistics, 2002. CA Cancer J Clin. 2005;55(2):74-108.

2. Jemal A, Siegel R, Xu J, Ward E. Cancer statistics, 2010. CA Cancer J Clin. 2010;60(5):277-300.

3. Goldstraw P, Crowley J, Chansky K, et al; for the International Association for the Study of Lung Cancer International Staging Committee; Participating Institutions. The IASLC Lung Cancer Staging Project: proposals for the revision of the TNM stage groupings in the forthcoming (seventh) edition of the TNM Classification of malignant tumours. J Thorac Oncol. 2007;2(8):706-714.

4. Asamura H, Goya T, Koshiishi Y, et al; for Japanese Joint Committee of Lung Cancer Registry. A Japanese Lung Cancer Registry study: prognosis of 13,010 resected lung cancers. J Thorac Oncol. 2008; $3(1): 46-52$.

5. Wang JS, Abboud RT, Wang LM. Effect of lung resection on exercise capacity and on carbon monoxide diffusing capacity during exercise. Chest. 2006;129(4):863-872.

6. Win T, Groves AM, Ritchie AJ, Wells FC, Cafferty F, Laroche CM. The effect of lung resection on pulmonary function and exercise capacity in lung cancer patients. Respir Care. 2007;52(6):720-726.

7. Qiao X, Tullgren O, Lax I, Sirzén F, Lewensohn R. The role of radiotherapy in treatment of stage I non-small cell lung cancer. Lung Cancer. 2003;41(1):1-11.
8. Marks LB, Fan M, Clough R, et al. Radiation-induced pulmonary injury: symptomatic versus subclinical endpoints. Int $J$ Radiat Biol. 2000;76(4):469-475.

9. Allen AM, Czerminska M, Jänne PA, et al. Fatal pneumonitis associated with intensity-modulated radiation therapy for mesothelioma. Int J Radiat Oncol Biol Phys. 2006;65(3):640-645.

10. Kahán Z, Csenki M, Varga Z, et al. The risk of early and late lung sequelae after conformal radiotherapy in breast cancer patients. Int $J$ Radiat Oncol Biol Phys. 2007;68(3):673-681.

11. Kong FM, Hayman JA, Griffith KA, et al. Final toxicity results of a radiation-dose escalation study in patients with non-small-cell lung cancer (NSCLC): Predictors for radiation pneumonitis and fibrosis. Int J Radiat Oncol Biol Phys. 2006;65(4):1075-1086.

12. Yom SS, Liao Z, Liu HH, et al. Initial evaluation of treatment-related pneumonitis in advanced-stage non-small-cell lung cancer patients treated with concurrent chemotherapy and intensity-modulated radiotherapy. Int J Radiat Oncol Biol Phys. 2007;68(1):94-102.

13. Ma J, Zhang J, Zhou S, et al. Association between RT-induced changes in lung tissue density and global lung function. Int J Radiat Oncol Biol Phys. 2009;74(3):781-789.

14. Gibbs IC, Loo BW Jr. CyberKnife stereotactic ablative radiotherapy for lung tumors. Technol Cancer Res Treat. 2010;9(6):589-596.

15. Brown WT, Wu X, Fayad F, et al. CyberKnife radiosurgery for stage I lung cancer: results at 36 months. Clin Lung Cancer. 2007;8(8):488-492.

16. Vahdat S, Oermann EK, Collins SP, et al. CyberKnife radiosurgery for inoperable stage IA non-small cell lung cancer: $18 \mathrm{~F}$-fluorodeoxyglucose positron emission tomography/computed tomography serial tumor response assessment. J Hematol Oncol. 2010;3:6.

17. Van der Voort van Zyp NC, Prévost JB, Hoogeman MS, et al. Stereotactic radiotherapy with real-time tumor tracking for non-small cell lung cancer: clinical outcome. Radiother Oncol. 2009;91(3):296-300.

18. Collins BT, Erickson K, Reichner CA, et al. Radical stereotactic radiosurgery with real-time tumor motion tracking in the treatment of small peripheral lung tumors. Radiat Oncol. 2007;2:39.

19. Collins BT, Vahdat S, Erickson K, et al. Radical CyberKnife radiosurgery with tumor tracking: an effective treatment for inoperable small peripheral stage I non-small cell lung cancer. J Hematol Oncol. 2009;2:1.

20. Stephans KL, Djemil T, Reddy CA, et al. Comprehensive analysis of pulmonary function Test (PFT) changes after stereotactic body radiotherapy (SBRT) for stage I lung cancer in medically inoperable patients. J Thorac Oncol. 2009;4(7):838-844.
Cancer Management and Research

\section{Publish your work in this journal}

Cancer Management and Research is an international, peer-reviewed open access journal focusing on cancer research and the optimal use of preventative and integrated treatment interventions to achieve improved outcomes, enhanced survival and quality of life for the cancer patient. The journal welcomes original research, clinical \& epidemiological

\section{Dovepress}

studies, reviews \& evaluations, guidelines, expert opinion \& commentary, case reports \& extended reports. The manuscript management system is completely online and includes a very quick and fair peerreview system, which is all easy to use. Visit http://www.dovepress.com/ testimonials.php to read real quotes from published authors. 